\title{
CRIMINALIZACIÓN, FEMINISMO, PRESIÓN POPULAR Y DERECHOS HUMANOS. EL CASO ESPAÑOL
}

\section{CRIMINALIZATION, FEMINISM, POPULAR DEMAND AND HUMAN RIGHTS. THE SPANISH CASE}

\author{
Jesús Victor Alfredo Contreras Ugarte ${ }^{l}$ \\ Investigador en el Instituto de Derechos Humanos \\ Facultad de Derecho - Universidad Complutense de Madrid \\ jesuco_amag@yahoo.es \\ España, Madrid
}

\section{SUMARIO}

- Introducción

- ¿Se puede hablar hoy de discriminación contra la mujer?

- La regulación de la discriminación en el ámbito del Derecho

- La regulación española de violencia contra la mujer cuando existe un vínculo de afinidad

- Percepciones finales

\section{RESUMEN}

En este trabajo busco despertar la mayor reflexión sobre una situación legal que está provocando la discriminación en contra del hombre por razón de su sexo y que, a su vez, beneficia a la mujer otorgándole privilegios procesales y normativos, por la misma mera razón. No niego la discriminación histórica que ha sufrido la mujer a través del tiempo y en este artículo dejo evidencia patente de ello y afirmo que dicha idea discriminatoria aún se mantiene viva en algunas cabezas, incluso en personajes connotados de nuestra sociedad. No obstante, en este artículo rechazo que esta situación pueda justificar que desde el Derecho se impongan normas legales que vejan la dignidad del hombre por el simple hecho de serlo. El Estado queriendo dar respuestas inmediatas y eficientes, sobre todo por la presión popular de algunas masas interesadas, ha terminado instaurando normas abusivas $\mathrm{y}$ desproporcionadas en contra del hombre. Poder vejar injustamente a un hombre en su dignidad, porque la ley lo facilite, también es violencia.

\begin{abstract}
In this work I seek to awake a reflection on the legal situation that is causing discrimination against men because of sex and that, in turn, benefits women granting them procedural and normative privileges, for the same reason. I do not deny the historical discrimination women have suffered over the time and in this article I give clear evidence of this and affirm that this discriminatory idea still remains alive in some heads, even in notorious persons of our society. However, in this article I reject that this situation can justify from the Law legal rules that harass the dignity of man for the simple fact of being. The State, wanting to give immediate and efficient answers, especially through the popular pressure of some interested people, has ended up establishing abusive and disproportionate norms against men. Being able to, unfairly mistreat a man in his dignity, because the law facilitates it, this is also violence.
\end{abstract}

\section{PALABRAS CLAVE}

Criminalización; prohibición de discriminación contra la mujer y contra el hombre; presión popular.

1 Abogado por la Universidad de San Martín de Porres; Especialista con Matrícula de Honor en Derechos Humanos por la Universidad Complutense de Madrid; Máster en Derechos Fundamentales, Especialista en Educación para la Ciudadanía y los Derechos Humanos, Máster en Estudios Avanzados en Derechos Humanos y, Doctor Sobresaliente Cum Laude en Estudios Avanzados en Derechos Humanos, por la Universidad Carlos III de Madrid. 


\section{KEY WORDS}

Criminalization; prohibition of discrimination against women and against men; popular demand.

\section{INTRODUCCIÓN}

Dar, en términos de derechos, un trato desfavorablemente desigual y peyorativo a una persona, es indudable que no es correcto y resulta inaceptable para nuestras sociedades modernas de la actualidad. Somos sociedades que declaramos abiertamente nuestra defensa $\mathrm{y}$ respeto hacia los derechos humanos $\mathrm{y}$, declarativamente, al menos, decimos que son iguales para todos. Solo hay que ver el panorama normativo, tanto del orden nacional como del internacional, para darnos cuenta que de declaraciones y normas formales no andamos nada escasos; todo lo contrario. Sin embargo, es cierto que, pese a toda esta normativa, existen aún determinados grupos sociales que sufren, históricamente, una discriminación que no ha sido superada del todo y requieren de cierto trato especial desde el ámbito normativo del Derecho. En este contexto, son necesarias medidas excepcionales que rectifiquen la situación de discriminación aún no superada del todo. Es aquí donde se justifican las llamadas acciones afirmativas. Hay quien prefiere llamarlas discriminaciones positivas, pero esto es un error dado que lleva a confusión porque la palabra discriminar tienen siempre una connotación excluyente y negativa.

La acción afirmativa supone la instauración de políticas encaminadas a dar un trato diferenciado a determinados grupos sociales que se encuentran especialmente afectados en sus derechos o que por sus características propias e históricas estos grupos están desfavorecidos y, por ello, requieren un trato normativo particular a fin de equipararlos en su posición social y ante los derechos de todos los demás. El trato ventajoso busca lograr el acceso a determinadas situaciones en igualdad de oportunidades y derechos a fin de acabar con la discriminación sufrida. Lo que se quiere es impedir la causa que suscita la discriminación o desventaja. Para Giménez Gluck (1999), las acciones afirmativas -a las que él llama acciones positivas- son las que otorgan un trato formalmente desigual para favorecer a determinados grupos sociales que poseen un rasgo diferenciador en común caracterizado por ser transparente e inmodificable y constituir cláusulas específicas de no discriminación.

Situándome en el tema de este artículo, empezaré reconociendo que es indiscutible que la mujer, históricamente, pertenece a uno esos grupos desfavorecidos ya que, en el tiempo, ha sido injustamente discriminada y menospreciada en la sociedad por la mera razón de su sexo; esto lo dejo fuera de toda discusión y duda. En otrora, no solo resultó puesta en una condición de execrable desventaja sino que además llegaban a necesitar el permiso del varón para muchas situaciones de su vida. También es cierto que, en la actualidad, la mujer aún viene siendo víctima de una violencia cometida por algunos -demasiados- varones que no logran superarse a sí mismos y que no entienden ni mejoran en sus conceptos de valor sobre lo que es su humanidad y la de todos los demás. No se trata de un problema que acontezca solo en personas con poca educación o de estratos sociales económicamente bajos pues la violencia contra las mujeres se ejerce en todo nivel intelectual, social y económico. Se trata de una conciencia estructural de dominación que desde niños se nos inculca a todos y que sin una buena educación, crítica y reflexiva en valores, lamentablemente, resulta imposible de extirpar. En este sentido, entonces, con las acciones afirmativas, se buscaría: "Compensar situaciones históricas de discriminación padecidas por ciertos grupos, mediante el reconocimiento de ventajas o beneficios que operen como alternativas rectificadoras de un criterio mecánico de igualdad" (Montoya Melgar, 2007, 74).

La educación que hoy se da, que resta importancia a materias que impulsan y fomentan la crítica y la reflexión sobre la sociedad y sus valores humanos preeminentes, es la gran cómplice de esta situación. La educación actual está más preocupada por formar simples individuos que se integren a los trabajos que el sistema económico ofrece en el mercado laboral y no se preocupa por ciudadanos formados y fortalecidos en sus capacidades de crítica y reflexión sobre todo lo existente. La conciencia reflexiva de nuestra humanidad (la de todos -tanto hombres como mujeres-) y la de nuestra reflexión propia sobre la realidad que nos rodea (es decir la conciencia sobre todo lo que hay) es algo que no le preocupa fomentar a la educación dominada por el mercado económico que 
Criminalization, feminism, popular demand and human rights.

The spanish case

hoy nos impone con vehemencia su espíritu de insaciable lucro. Se trata de convertir a las personas en autómatas los que, alcanzada la mayoría de edad, deban incorporarse a la sociedad según los requerimientos del mercado de trabajo, es decir, según lo que le interese al sistema económico imperante. Se espera de estos autómatas, que no le increpen nada sustancial al sistema en el que viven, dejándose llevar y haciéndose parte -sin una reflexión auténtica y propia- de la realidad según como está. Sin duda, en este escenario, los grupos históricamente desfavorecidos tienen poca posibilidad de solucionar, sustancialmente, la discriminación que sufren $\mathrm{y}$, menos posibilidad todavía, de acabar con la violencia de la que son víctimas como consecuencia de esta situación estructural.

Entonces, que quede claro, que no niego que la mujer ha sufrido una discriminación histórica y cultural por razón de su sexo, lo que la incorpora, lastimosamente, en los llamados grupos desfavorecidos o desaventajados de la sociedad. Empero, esto es una cosa y otra muy diferente es que por razón de esta situación, que no niego que sea lamentable, se deba crear y justificar otra de igual connotación. Actualmente, las cosas han mejorado mucho en cuanto a la situación de la mujer en la sociedad y aunque aún existen problemas de discriminación y violencia en contra de las mujeres, tampoco se trata de magnificar la situación y pretender criminalizar a todos los hombres por la mera razón de serlo. Y mucho me temo, que se está cayendo en este grave error que es propiciado por grupos radicales y poco reflexivos que lo único que intentan es la confrontación y la exagerada $\mathrm{o}$ falsa victimización, a veces, por intereses meramente espurios de subvención y poder. No todo lo que se mueve en contra de la mujer es machismo o supone, prima facie ni per se la mal llamada violencia de género. Muchas veces las causas son de otra índole y no tienen nada que ver con el hecho o con la actitud del hombre de sentirse superior a la mujer por el menosprecio que siente hacia ella en cuanto a su condición de mujer, que es de lo que, realmente, se trata el machismo. Hay quien defiende que la violencia de género se produce cuando existe una violencia que afecta a las mujeres por el mero hecho de serlo. Esto es un error, o en todo caso se queda corto, porque si la afectada es una mujer y la afectante otra mujer (en una pareja lesbiana, por ejemplo), entonces, ya no es violencia de género. Ergo, eso que dicen ciertos grupos feministas que la integridad, la dignidad y la libertad de las mujeres es lo que les preocupa independientemente al ámbito en el que se produzca, no es cierto porque si esto se produce en el ámbito de una pareja de lesbianas, aquí esto no les importa a quienes se llaman defensoras de los derechos de las mujeres; se trata de ir en contra de los hombres por el solo hecho de ser hombres. Esta situación suena más a un ánimo de destrucción o vejación del hombre por razón de su sexo, que de defensa y protección de los derechos de las mujeres. Luego, el mejor argumento en el que se amparan es en el de las estadísticas, las que por supuesto y como siempre no indican precisamente la realidad de las cosas y, más bien, suelen manipularse y, en el mejor de los casos, equivocarse y no acertar en sus conclusiones. Unas estadísticas donde se mete, además de los casos ciertos, todo lo que se antoja entender por machismo y por violencia de género, cuando, en demasiados casos, no tienen nada que ver con esto y se debe a otras causas o, directamente, no se debe a nada porque son denuncias falsas.

Antes de que el amable lector se confunda y crea que soy un machista despiadado de esos que creen que la mujer a la cocina y el hombre a trabajar, me permito adelantarme informándole que no soy machista, que me resulta repugnante que un hombre ejerza violencia contra una mujer -al igual que una mujer o cualquier persona la ejerza contra otra mujer o contra otra cualquier persona-, no creo que el varón sea superior a la mujer por naturaleza, ni nada, nada por el estilo. El menospreciar o violentar a una mujer por razón de serlo y por creerse superior a ella, es algo que me parece execrable, injusto e inaceptable para cualquier persona que se considere medianamente civilizada y correcta. Claro está, que el pretender justificar una magnificada criminalización para lograr una generalizada discriminación legal de trato en contra del hombre y por la mera razón de su sexo, también me parece absolutamente injusto, execrable e igual de inaceptable.

\section{¿SE PUEDE HABLAR HOY DE DISCRIMINACIÓN CONTRA LA MUJER?}

No desconozco ni me dejo de indignar con las evidencias históricas de la situación que ha sufrido la mujer en el mundo ni con que 
las conciencias más ilustradas hayan sido parte de este grave error. Por ejemplo, sé bien que Juan Jacobo Rousseau, sin recato alguno y explícitamente infravaloró a la mujer colocándola en una posición de debilidad existencial, de subordinación y, con ello, al servicio y favor del varón. Según él, la mujer cuando se esfuerza por usurpar los derechos de los hombres termina quedándose en una situación de vasallaje. Advirtamos aquí que Rousseau con el solo hecho de hablar de una supuesta usurpación de los derechos de los hombres, ya evidencia que este connotado autor tenía una conciencia privativa de ciertos derechos que le corresponderían en exclusividad a los hombres por el solo hecho de serlo, como si esto fuera un mérito y el ser mujer lo contrario. Esto, con certeza, nos muestra, claramente, que estamos ante la presencia de una conciencia discriminadora que relega a la mujer de esos que serían los derechos exclusivos de los hombres por ser tales. Y adviértase también, que no me estoy refiriendo a cualquier personaje medianamente connotado, sino que estoy hablando de un ilustrado a quien muchos consideran el padre de la democracia y, otros, incluso, lo consideran como uno de los mejores entendidos de la dignidad humana. Ya vemos que esto, cierta y objetivamente, no es así. Podemos comprobar todo esto que digo simplemente leyendo su obra Emilio o de la educación -obra que, por cierto, es considerada de obligada lectura para aquellos que se dedican a la carrera de Magisterio-. Leyéndola, nos encontraremos con cuatro primeros capítulos donde se hace un desarrollo narrativo sobre un personaje llamado Emilio. Dicha obra, es cierto, puede considerarse como una gran guía para la enseñanza moderna pues reboza de una innegable riqueza intelectual tremendamente útil, sobre todo para el campo de la educación. Sin embargo, esta obra cuenta con un último y quinto capítulo que, a decir verdad, no es tan rico ni sirve ya tanto a la enseñanza moderna ni sirve de ejemplo para nada ni para nadie. Este quinto capítulo intitulado Sofía o la mujer, afirma cosas que hoy nos causarían una gran irritación por ser auténticos dislates y desatinos que no se corresponden con la supuesta grandeza intelectual de este autor ilustrado. Y, claro, no vale esgrimir el consabido argumento de que hay que tener en cuenta el contexto y el tiempo histórico en que Rousseau escribía, como algunos despistados esgrimen para justificar tamañas insensateces. Las afirmaciones que Rousseau hace en ese quinto capítulo, no pueden simplemente justificarse por el contexto y menos para alguien del que se afirma y se supone tamaña e ilustre capacidad intelectual.

Lo que queda muy claro, de la obra de Rousseau, es que, para él, el varón es el ser activo y fuerte y, la mujer, el ser débil y pasivo. Y si llamo a las cosas por su nombre, sin usar cortapisas ni maquillajes para disimularlo o atenuarlo, puedo afirmar que Rousseau, en ese su quinto capítulo, relega a la mujer y la menosprecia abiertamente, cosificándola y confinándola a un rol de objeto para la satisfacción y placer del varón; lo que propugna Rousseau en ese quinto capítulo es una teoría que actualmente reconoceríamos como el mejor arquetipo del machismo; mejor dicho, hoy Rousseau no sería considerado un ilustrado sino más bien el mejor ejemplo de un machista a ultranza $\mathrm{y}$ un discriminador de seres humanos en toda regla. En ese capítulo quinto se pueden encontrar otras y más gruesas afirmaciones ilustradas de este connotado personaje que resultan pertinentes para fijar mi posición en este trabajo. Dice Rousseau que el destino específico de la mujer es agradar al hombre, pues el reconocimiento del varón consiste en un poder y solo por su fuerza agrada. Y dice más todavía; sin embargo, prefiero citar parte de ese capítulo quinto, tal cual, ya que no tiene desperdicio alguno y permitirá al lector entender mejor lo que aquí afirmo:

(...) cuando (...) se quejan las mujeres de la desigualdad que han establecido los hombres, no tienen razón; esta desigualdad no es institución humana, o a lo menos no es hija de la preocupación, sino de la razón (...) todo marido infiel (...) es un inhumano y un injusto; pero hace más la mujer infiel, pues disuelve la familia y quebranta todos los vínculos de la Naturaleza (...) junta la perfidia con la infidelidad. (...) Sostener vagamente que son iguales ambos sexos, y unas mismas sus obligaciones, es abandonarse a declaraciones vanas (...) Decís que no siempre las mujeres están en cinta. No; mas su destino peculiar es estarlo. (...) demostrado que ni en cuanto al carácter ni al temperamento están ni deben estar constituidos del mismo modo el hombre y la mujer, se infiere que no se les debe dar la misma educación. 
(...) cuando procuran usurpar nuestras ventajas, no abandonan la suya (...) sucede que no pudiendo amalgamar bien unas con otras porque son incompatibles (...) no pueden (...) competir con nosotros, perdiendo así la mitad de su precio. (...) los hombres penden de las mujeres por sus deseos; las mujeres penden de los hombres por sus deseos y necesidades; mejor subsistiéramos nosotros sin ellas que ellas sin nosotros. Para que tengan lo necesario en su estado, es preciso que se lo demos, que se lo queramos dar, que las reputemos dignas (...) Por la misma ley de la Naturaleza, las mujeres (...) están a merced de los hombres: no basta con que sean estimables, es preciso que sean estimadas (...) El hombre, cuando obra bien, sólo depende de sí propio y puede arrastrar el juicio del público; pero la mujer, cuando obra bien, sólo tiene hecha la mitad de la tarea (...) toda la educación de las mujeres debe ser relativa a los hombres. Agradarles, serles útiles, hacerse amar y honrar de ellos, educarlos cuando niños, cuidarlos cuando mayores, aconsejarlos, consolarlos, hacerles grata y suave la vida; éstas son las obligaciones de las mujeres en todos los tiempos y esto lo que desde su niñez se les debe enseñar. (Rousseau, 2011, página 362 y ss.)

Las palabras de Rousseau sobre la mujer, tienen que indignar a cualquier conciencia inteligente $\mathrm{y}$ formada en valores $\mathrm{y}$ derechos humanos. Esto debe molestar tanto a mujeres como a varones; estas aberrantes afirmaciones de este connotado personaje de la historia resultan reprochables para todo ser humano noble, crítico y decente, y no por ser de uno $\mathrm{u}$ otro sexo, sino por su propia conciencia $\mathrm{y}$ sustancialidad humana.

Teniendo en cuenta que el Emilio o de la educación es una obra de 1762 (siglo XVIII) y que los conceptos que Rousseau vierte en ese capítulo quinto son de un otrora tan largo que pudiéramos pensar que este es un tema ya superado en nuestra actualidad tan moderna y avanzada. Pensar esto sería un error ya que los descarríos de Rousseau sobre la mujer no se han superado del todo o, al menos, se puede decir que aún hay connotados que viven convencidos por esta conciencia equivocada de discriminación, menosprecio y relego de nuestra humanidad. Asimismo, si revisamos a otros connotados personajes de antaño advertiremos que no solo Rousseau era quien caía en estos descarríos; es cuestión de echarle un vistazo esmerado y crítico a las obras de la historia de nuestra humanidad, pero que, para este artículo, por cuestiones de espacio, solo lo dejo anotado como incentivo intelectual para quien quiera investigar.

De lo que me quiero ocupar ahora es de la actualidad, pues he dicho que estas posturas discriminatorias se siguen manteniendo. Hoy, en pleno siglo XXI, estos conceptos los volvemos a reconocer y a escuchar en personas con cargo político y de relevancia social y de las que se esperaría una mejor conciencia y formación sobre los valores propios de la humanidad ya que se les supone una mejor y sólida educación -igual como se suponía de Rousseau-. Recordaré aquí las actuales declaraciones del eurodiputado polaco Janusz Korwin-Mikke, quien el 1 marzo de 2017 abiertamente $y$ sin rubor alguno e incluso sabiéndose grabado por cámaras de televisión internacionales, tuvo la valentía de esgrimir ardorosamente, en el Parlamento Europeo, una argumentación por la que dejaba clara su defensa para que las mujeres ganen menos por su -según él- realidad de inferioridad frente a los hombres. Sus declaraciones no dan lugar a duda alguna sobre lo que él piensa; es muy claro en lo que dice y sostiene; cito aquí lo que dijo exactamente:
¿Sabe usted qué papel ocupaban las mujeres en las Olimpiadas griegas? ¿La primera mujer griega? Se lo digo yo, el puesto 800. ¿Sabe usted cuántas mujeres hay entre los primeros cien jugadores de ajedrez? Se lo diré: ninguna. Por supuesto, las mujeres deben ganar menos que los hombres porque son más débiles, más pequeñas, menos inteligentes. (El Mundo, 2017, párrafo 2)

Se puede decir que este eurodiputado vive en las ideas del siglo XVIII y que parece que sí se ha leído e interiorizado muy bien ese capítulo quinto de la obra de Rousseau. Está claro que estas declaraciones son completamente reprochables, se hagan en la época en que se hagan, en el contexto que sea y las haga quien las haga.

No obstante, lo que más me preocupa es que las ideas de este eurodiputado, mucho me 
temo, que no sean aisladas ni se limiten a un simple caso de valentía o exabrupto emotivo que ha hecho que este eurodiputado diga lo que dijo públicamente y sin tapujos. Este tipo de situaciones las tenemos que tomar como un llamado de atención hacia la crisis de valores que sigue y viene sufriendo nuestra humanidad y que muchos disimulan aprendiendo a gestionar sus actos con lo políticamente correcto al momento de decir las cosas en público, aunque en privado y en el fondo esas ideas desafortunadas y discriminatorias, sigan estando en las conciencias sinceras de muchos connotados y no connotados de nuestra modernidad. El eurodiputado solo sería alguien que perdió el control de su disimulo o, simplemente, no le interesa decir lo que no cree ni le tiene apego a la forma de lo políticamente correcto. Advirtamos también que ese eurodiputado polaco para lograr su cargo ha sido elegido y votado por muchos ciudadanos europeos, y si ellos conocían este ideario de su candidato ya podemos suponer que él no es el único que piensa y defiende lo que dijo.

Otra situación de actualidad la encontramos en lo que se podía leer en la prensa del 23 de octubre de 2017 donde se refleja claramente la mentalidad discriminatoria que aún se mantiene en profesionales a los que se les supone una mayor sensibilidad y sensatez para los derechos humanos. Es el caso de un juez, claramente desfasado y equivocado en sus convicciones humanas, que dicta resoluciones con criterios auténticamente retrogradas lo que, más bien, debería merecerle el despido inmediato y hasta un tratamiento en valores cívicos y humanos antes de pretender volver a un cargo público. Me estoy refiriendo al caso del juez portugués que justificó el secuestro y la paliza propinada a una mujer, simplemente porque esta le fue infiel a su marido. El magistrado Neto de Moura dicta su resolución judicial diciendo lo siguiente:

El adulterio cometido por una mujer es un gravísimo atentado contra el honor y la dignidad del hombre (...) la violencia ejercida por el hombre se ve con cierta comprensión, ya que ha sido traicionado, vejado y humillado por la mujer. (Hernández-Morales, 2017, párrafo 2)

Son estas y otras lindezas las que se pueden leer en esta noticia. Es algo realmente inaceptable, pero sucede y sigue sucediendo; y si volvemos a la cita anterior que hice de Rousseau, veremos que el argumento discriminatorio de este juez también se le parece mucho.

En este contexto de crisis de valores, está claro que, para la mujer, se hacen necesarias acciones afirmativas a su favor en busca de una mejor solución a este problema del ayer $\mathrm{y}$, como he advertido, también del hoy que nos rodea. Nótese bien que hablo de buscar una solución al problema y no de buscar una solución a su problema -al de la mujer- y esto, aviso, que lo hago intencionadamente. Me explico: esta situación no es un problema privativo de la mujer -al igual que los derechos no le son únicamente privativos al varón- sino que es un problema que nos afecta y compete a toda la sociedad en su conjunto como humanidad que es. También quiero dejar claro que no estoy sosteniendo que la acción afirmativa sea siempre necesaria y correcta; más bien creo que cada una de ellas debe ser excepcional, limitada en el tiempo y proporcional en cuanto al respeto del derecho de los demás.

Además, sostengo, que es primordial y crucial que con la acción afirmativa empleada no se provoque otra discriminación ni menosprecio sobre cualquier otro grupo de personas, siendo inaceptable el pretender justificar la creación de nuevas víctimas -esta vez hombres- por una supuesta necesidad de mayor protección al otro grupo porque ya es sabido que, históricamente, es víctima de discriminación o violencia. Pretender lograr que no se violenten los derechos y la dignidad de la mujer, violentando y vulnerando los derechos y la dignidad del hombre, no es ni será nunca lo correcto; ambas vulneraciones son igual de inaceptables. Esta forma de gestionar la lucha en contra de la discriminación y violencia que sufre la mujer, lo que hace es sostener una suerte de jerarquización de víctimas en donde la mujer es la que tiene el derecho a ser sobreprotegida con normas legales que discriminan al hombre por razón de su sexo porque, supuestamente, ellas son más las afectadas y lo han sido por mucho más tiempo. Esto es un despropósito total y desautoriza y hace caer en el desatino a quien pretende sostener esto desde el ámbito de los derechos humanos; y no importa que sean pocas las denuncias falsas. En derechos humanos importan tanto los derechos de uno como los de miles. Los derechos humanos defienden la cualidad de ser seres humanos, sea cual sea el número de afectados; no es 
un tema que recién tenga relevancia a partir de un concepto de cantidad. La defensa de los derechos humanos no tiene sentido a partir de tal o cual número de afectados. Es suficiente que haya una sola denuncia falsa $\mathrm{y}$ un trato inmediato $\mathrm{y}$ vejatorio posibilitado por una norma legal, para que esa norma sea detestable, abrogable y completamente contraria a la defensa de los derechos humanos y a la dignidad que se defiende desde los postulados de la igualdad en derechos. Esto lo dejo muy claro puesto que considero que todos los seres humanos tenemos el mismo derecho de ser respetados y considerados en nuestra dignidad y valor. En una sociedad democrática y civilizada no cabe la discriminación ni el menosprecio hacia un ser humano o hacia un grupo humano determinado, sea varón o mujer, sea niño o niña, joven o anciano, sea con distinta capacidad o no, sea uno o sean millones, etcétera. El respeto a los derechos humanos es una obligación de todos y para todos por igual. Todos los seres humanos tenemos el deber de exigirnos contribuir activamente a la protección y satisfacción de los derechos humanos de los demás: "todos debemos actuar positivamente para la realización de esos derechos en los otros" (Barranco, 1996, 64). Discriminar, vejando y menospreciando derechos de otros, es inaceptable desde todo punto de vista; por mucho que se le quiera maquillar, a veces, con el nombre de "discriminación positiva". El uso de acciones afirmativas que causan discriminación en contra de un grupo de seres humanos no puede sustentarse, ni mucho menos justificarse, en la necesidad de protección a favor del otro grupo que históricamente es reconocido como el desfavorecido. Proteger a unos o a unas, vejando y afectando los derechos de los otros, está fuera de todo marco de justificación coherente en la defensa razonable de los derechos humanos y de la prohibición de discriminación en contra de cualquier ser humano. Para mejorar la protección de la dignidad de un grupo resulta detestable tener que menospreciar y dañar la dignidad de otro, por culpable, causante o responsable que se le crea. Un mal no se quita con otro mal, ni uno justifica al otro. Por tanto, como resalta bien el profesor Germán Gómez Orfanel, se debe pues constatar que efectivamente existe una discriminación social en perjuicio del grupo al que se pretende favorecer, debiendo tener las medidas de la acción afirmativa un carácter temporal:
Dado que la acción positiva puede entrar en conflicto con otros derechos fundamentales o bienes constitucionales, deberán superar un escrutinio acerca de su razonabilidad y proporcionalidad (idóneas, necesarias, y generadoras de un beneficio mayor que los sacrificios que el trato de favor pueda haber producido). (Gómez, 2008. Página 389)

\section{LA REGULACIÓN DE LA DISCRIMINACIÓN EN EL ÁMBITO DEL DERECHO}

El rechazo de todo tipo de discriminación, no es algo que se asiente, únicamente, en el subjetivismo reflexivo, lógico y coherente de quienes entendemos que los derechos humanos y el respeto a la persona humana, como tal, resultan inquebrantables y defendibles para todos por igual. Y el deber de detestar toda discriminación, no es una mera opinión subjetiva de mi parte. En Derecho se le conoce como prohibición de discriminación y la podemos encontrar en muchas normas legales, tanto de carácter nacional como internacional.

La prohibición de discriminación, básicamente, se trata del derecho humano a no ser discriminado. En este sentido, el derecho humano a no ser discriminado le otorga a cada hombre, mujer, niña o niño, es decir a todos por igual, el derecho a la no distinción, exclusión, restricción o preferencia, por motivos del sexo, raza, color, origen nacional o étnico, religión, opinión política, edad, o cualquier otra condición que tenga por objeto el afectar o deteriorar gravemente el goce de los derechos $\mathrm{y}$ libertades fundamentales. Este derecho incluye, claro está, respetar y proteger el derecho a la igualdad de trato entre hombres y mujeres tanto en la familia como en la sociedad, $\mathrm{y}$ esto incluye, por supuesto, el trato igual en los derechos que defiende la legalidad. Si se protege la dignidad una, sobre entendido está, que esto implica proteger también la dignidad del otro, y con el mismo valor y esfuerzo que merecen los dos como seres humanos que son.

Si nos tomamos el tiempo de revisar la normativa internacional, veremos que en la Declaración Universal de Derechos Humanos de 1948, se declara que todos los seres humanos nacen libres e iguales en dignidad y derechos $\mathrm{y}$ que todos tienen los mismos derechos $\mathrm{y}$ 
libertades, sin distinción alguna por razón de sexo. Todos son iguales ante la ley y tienen, sin distingo alguno, derecho a igual protección de la ley. Resulta obvio advertir que en esta Declaración, implícitamente, se reconoce que los hombres y mujeres tienen el derecho a igual protección contra toda discriminación y trato peyorativo y contra toda cualquier situación que la provoque.

Por su parte el Pacto Internacional de Derechos Económicos, Sociales y Culturales de 1966 establece el compromiso de los Estados de garantizar el ejercicio de los derechos culturales, económicos y sociales, sin discriminación alguna por motivos de sexo. Aquí también, los Estados partes se comprometen a asegurar a los hombres y a las mujeres igual título para gozar de todos los derechos económicos, sociales y culturales. El espíritu de igual trato para todos e igual dignidad, también se deja ver, claramente, en esta norma internacional.

Luego, el Pacto Internacional de Derechos Civiles y Políticos de 1966, establece que los Estados deben garantizar el respeto de todos los individuos sin discriminación alguna por motivos del sexo. Toda persona cuyos derechos o libertades reconocidos en ese Pacto hayan sido violados podrá interponer un recurso efectivo. Además se establece el compromiso de garantizar a hombres y mujeres la igualdad en el goce de todos los derechos civiles y políticos. Además. se establece, claramente, que todas las personas son iguales ante los tribunales y cortes de justicia y que toda persona tiene derecho a ser oída públicamente y con las debidas garantías por un tribunal competente, independiente e imparcial establecido por la ley, en la substanciación de cualquier acusación de carácter penal formulada contra ella. Hay que poner especial atención cuando en este pacto se dice que "todas las personas son iguales ante la ley y que tienen derecho sin discriminación a igual protección de la misma". En esta norma sí aparece expresamente estipulada la prohibición de discriminación cuando dice que se dispone que la ley prohibirá toda discriminación además de garantizar a toda persona una protección igual y efectiva contra toda discriminación por motivo de su sexo. Esta norma internacional dispone manifiestamente la prohibición de discriminar por razón de sexo.
Por otro lado, es también de especial relevancia la Convención para la Eliminación de todas las Formas de Discriminación contra la Mujer de 1979. En ella se establece que la expresión discriminación contra la mujer indicará toda distinción, exclusión o restricción basada en el sexo que tenga por objeto o por resultado menoscabar o anular el reconocimiento, goce o ejercicio de la mujer de los derechos humanos y las libertades fundamentales. Es decir, se trata de prohibir e impedir la discriminación por la mera razón del sexo; se condena así la discriminación por razón de sexo en contra de la mujer, en todas sus formas; los Estados parte se comprometen a consagrar, en sus constituciones nacionales y en cualquier otra legislación apropiada el principio de la igualdad del hombre y de la mujer; se comprometen a adoptar medidas adecuadas, legislativas y de otro carácter, con las sanciones correspondientes, que prohíban toda discriminación contra la mujer; se comprometen a establecer la protección jurídica de los derechos de la mujer sobre una base de igualdad con los del hombre. Además, dispone que -y para este trabajo esta parte es muy relevante- los Estados se comprometen a reconocer a la mujer la igualdad con el hombre ante la ley para eliminar la discriminación contra la mujer en todos los asuntos relacionados con el matrimonio y las relaciones familiares. Como vemos, no cabe duda que de lo que se trata es de eliminar y prohibir la discriminación por razón del sexo, que es donde las mujeres resultan especialmente afectadas. No obstante, nótese bien que no se trata de favorecer y promover una igual discriminación en contra de los hombres para lograr perjudicarlos haciéndolos padecer vejaciones en sus derechos y dignidad a fin de que esto sirva como instrumento que posibilite la eliminación de la discriminación sufrida por las mujeres. Es decir, no se trata de un intercambio de discriminaciones en donde el provocar una discriminación quede justificado por, supuestamente, paliar o acabar con la otra. Es la misma Convención la que lo deja claro cuando dispone que la adopción por los Estados de medidas especiales de carácter temporal encaminadas a acelerar la igualdad de facto entre el hombre y la mujer no se considerará discriminación, sin embargo, establece que de ningún modo llevará dentro de sí, como consecuencia, el mantenimiento de normas desiguales o separadas. Más clara $\mathrm{y}$ contundente no puede ser esta norma con respecto a este asunto. 
Si seguimos revisando la normativa internacional nos toparemos con compromisos realizados por los gobiernos en grandes cumbres de las que se puede notar, manifiestamente, la importancia que tiene la prohibición a toda forma de discriminación. Veamos algunas de ellas.

En la Declaración y Programa de Acción de Viena de 1993 (Declaración de Viena, aprobada por la Conferencia Mundial de Derechos Humanos) se habla del respeto a los derechos humanos y las libertades fundamentales sin, distinción alguna. Esta es una regla fundamental de las normas internacionales de derechos humanos, además se afirma que la erradicación de todas las formas de discriminación basadas en el sexo son objetivos prioritarios de la comunidad internacional. Está claro que el espíritu de esta Declaración es acabar con toda forma de discriminación que se fundamente en la razón del sexo, y esto incluye a los dos sexos, no solo a la erradicación de la discriminación sufrida por la mujer.

En la Declaración de Copenhague de $1995^{2}$ (en la Cumbre Mundial Sobre Desarrollo Social) se establece el compromiso de promover la integración social, fomentando sociedades estables, seguras y justas, basadas en la promoción y protección de todos los derechos humanos así como en la no discriminación. Con ese fin, se comprometen los Estados a fortalecer políticas y estrategias encaminadas a eliminar la discriminación en todas sus formas y a lograr la integración social sobre la base de la igualdad y el respeto de la dignidad humana; se comprometen a promover el pleno respeto de la dignidad humana y a lograr la igualdad y la equidad entre el hombre y la mujer, promulgando y aplicando leyes y políticas encaminadas a combatir y eliminar todas las formas de discriminación.

En la Declaración de Beijing de $1995^{3}$ (surgida de la Cuarta Conferencia Mundial sobre la Mujer) se declara la decisión de remover todo obstáculo hacia el logro de la equidad de género; es decir, hacia el logro de la igualdad del género, basada en el deber y en la conciencia de un trato justo para todos.

Es muy importante también tener en cuenta el Convenio para la Protección de los Derechos 2 Declaración de Copenhague Sobre Desarrollo Social, Copenhague, 12 de
marzo de 1995 , compro. $4^{\circ}$ y $5^{\circ}$.

3 Declaración de Beijing, Beijing, 15 de septiembre de 1995, aparta. $24^{\circ}$.
Humanos y de las Libertades Fundamentales de $1950^{4}$ (más conocido como el Convenio Europeo de Derechos Humanos o Convención Europea de Derechos Humanos, o también conocido como Convenio de Roma). Este Convenio contiene una disposición específica en tanto a la prohibición de discriminación sobre los derechos que él contiene, y establece que el goce de los derechos y libertades reconocidos en ese Convenio ha de ser asegurado sin distinción alguna, especialmente por razones de sexo. Este Convenio determina claramente que se debe asegurar el goce de los derechos y libertades sin distinción alguna por razón de sexo; es decir, se deben asegurar los derechos y libertades tanto a los hombres como a las mujeres, sin que para ello, se discrimine a uno de los dos. Es lógico y coherente que tenga que ser así, además de ser obvio y evidente para los postulados que sustentan, correctamente, el discurso de los derechos humanos.

Luego, en el Protocolo 12 a la Convención Europea de Derechos Humanos -Convención ya citada en el acápite inmediato anteriordel año 2000, se establece una prohibición general de discriminación. Aunque es cierto que el artículo $14^{\circ}$ de la Convención Europea de Derechos Humanos ya introdujo una prohibición de discriminación, esta se refería únicamente a la discriminación que afecta la aplicación de los derechos proclamados en la propia Convención. La diferencia radica en que el Protocolo 12 añade la prohibición de discriminación al goce de cualquier derecho previsto por la ley, o sea, de cualquier derecho que la legislación interna del Estado signatario reconozca a las personas. Los motivos por los que no se puede discriminar son los mismos ya recogidos en el artículo 14 de la Convención Europea de Derechos Humanos. Además, el Protocolo 12 prohíbe que nadie sea discriminado por una autoridad pública, lo que extiende la prohibición y aumenta las garantías. Si bien el Protocolo 12 reitera que el principio de no discriminación no impide a los Estados tomar medidas para promover una igualdad plena y efectiva; sin embargo, estas medidas, solo pueden existir cuando respondan a una justificación objetiva y razonable. Legislar privilegiadamente a favor de la mujer, criminalizando al hombre de manera general, para poder darle a él un trato legalmente

\footnotetext{
4 Convenio para la Protección de los Derechos Humanos y de las Libertades Fundamentales, Roma, 04 de noviembre de 1950, art. $14^{\circ}$.
} 
discriminatorio y vejatorio de su dignidad por la mera razón de su sexo, no tiene justificación objetiva alguna ni, por supuesto, es razonable desde ningún punto de vista.

Asimismo, en la Carta Social Europea de 1961, también aparece la prohibición de discriminación por razón de sexo en cuanto a los trabajadores, estableciéndose que los trabajadores tienen derecho a la igualdad de oportunidades y de trato en temas de empleo y de profesión, sin discriminación por razón del sexo. Una vez más advertimos el espíritu de las normas internacionales para oponerse a todo tipo de trato desigual y discriminatorio por razón del sexo.

De otro lado, nos encontramos con la Carta de los Derechos Fundamentales de la Unión Europea del año 2000 (conocida también como Carta de Niza). Esta norma internacional europea, establece que todos somos iguales frente a la ley; también establece la prohibición de discriminación y, además, dispone que la igualdad entre hombres y mujeres debe ser garantizada sin importar el ámbito del que se trate.

Después de este recorrido de normas internacionales, si dejamos este ámbito internacional y nos evocamos al ámbito nacional español, también nos toparemos con la referida prohibición de discriminación.

En la vigente Constitución española de 1978, se establece que:

1. Los ciudadanos y los poderes públicos están sujetos a la Constitución y al resto del ordenamiento jurídico. 2. Corresponde a los poderes públicos promover las condiciones para que la libertad y la igualdad del individuo y de los grupos en que se integran sean reales y efectivas; remover los obstáculos que impidan o dificulten su plenitud (...). Los españoles son iguales ante la ley, sin que pueda prevalecer discriminación alguna por razón de (...) sexo (...). (Artículo 9 y 14)

También se establece en el artículo 149.1.1a, de la citada Constitución, que el Estado tiene competencia para la regulación de las condiciones básicas que garanticen la igualdad de todos los españoles en el ejercicio de los derechos y en el cumplimiento de los deberes constitucionales. Es decir, en la Constitución española se dispone lo mismo que en las normas internacionales: en España no debe predominar discriminación alguna por razón de sexo.

Por último, me referiré a la ley orgánica $3 / 2007$, de 22 de marzo, para la igualdad efectiva de mujeres y hombres. En esta ley española, se incorpora el llamado principio de igualdad de trato entre mujeres y hombres y se incorpora, además, la integración del principio de igualdad en la interpretación y aplicación de las normas. Así pues, tengamos en cuenta que, por un lado, el principio de igualdad de trato entre mujeres y hombres supone la ausencia de toda discriminación, directa o indirecta, por razón de sexo. Por otro lado, la integración del principio de igualdad en la interpretación y aplicación de las normas supone que la igualdad de trato y de oportunidades, entre mujeres $\mathrm{y}$ hombres, es un principio informador del ordenamiento jurídico y, como tal, se integrará y observará en la interpretación y aplicación de las normas jurídicas. Es paradójico notar que esta igualdad promovida jurídicamente, no ha sido ajena ni siquiera a los alegatos más acérrimos del feminismo. Leed lo que escribe Carla Lonzi (1981) desde su posición feminista: "La igualdad es un principio jurídico: el denominador común presente en todo ser humano al que se le haga justicia" (página 16). Y esto es algo que si se pregunta a cualquiera que se diga feminista lo va a reafirmar con total contundencia; sin embargo, a la hora de confrontarle con ciertas normas jurídicas que no cumplen con este principio de igualdad jurídica común a todo ser humano y que más bien otorga un común denominador de privilegios legales únicamente para la mujer facilitando un trato jurídico de desigualdad en contra del hombre, en este momento el discurso de ese o esa que se dice feminista cambia y ya no es tan contundente. Se pasa a matizar el principio de igualdad jurídica con conceptos subjetivos de supuesta necesidad o se busca la trampa mediática de criminalizar directamente al hombre en casos concretos antes de que estos sean resueltos judicialmente -situación que, por cierto, le viene muy bien a ciertos medios de comunicación sensacionalistas a los que solo les importa tener más audiencia para ganar más dinero-; luego se minimizan y se desmerecen estadísticas de denuncias falsas que hacen muchas mujeres inescrupulosas, o se magnifican y manipulan caso concretos para hacer estadísticas donde se mete todo lo que se 
parezca a la mal llamada violencia de género para engrosar cifras y casos que en muchas ocasiones no tienen nada que ver con la violencia contra la mujer que se produce como consecuencia de la discriminación por razón de su sexo. La violencia puede tener su germen en muchas causas; hay que analizar cada caso concreto para saber de qué se trata y no, majadera y oportunistamente, etiquetar todo como violencia de género porque la denunciante es una mujer y el supuesto agresor es un hombre. Esta forma antojada y oportunista de etiquetar a la violencia provoca la discriminación por razón del sexo en contra del hombre e impide que se identifique el verdadero problema a fin de aplicarle las medidas correctivas que realmente correspondan. De no ser así, pasa lo que está pasando: las normas que luchan contra la violencia que sufre la mujer a causa de la discriminación por razón de su sexo, son insuficientes y casi totalmente ineficientes. En un problema primero se identifica la causa, luego se deciden las medidas correctivas aplicables a esa causa y, por último, se aplican pero según corresponda al tipo de causa que generó la violencia. Aplicar de manera general las mismas medidas correctivas y legales a todo lo que se etiqueta negligente y neciamente como machismo o violencia de género es un grave error porque, como dije, no toda violencia contra la mujer es consecuencia del machismo ni del menosprecio o discriminación por razón de su sexo. Pretender que todo lo sea para engrosar falsamente las estadísticas de maltrato es una ligereza que lleva a producir normas legales y a potenciar presupuestos, que no son más que una estafa de eficiencia $\mathrm{y}$, con ello, toda una falacia de solución.

Pues bien, luego de todo este recorrido de normas, se puede constatar, sin lugar a dudas, que existe reconocido, a nivel nacional e internacional, una prohibición de discriminar por razón de sexo. En lógica consecuencia de ello, también está prohibido perjudicar la dignidad de un sexo en favor del otro. Sin embargo, dejo claro que, si bien toda discriminación está prohibida, eso no quita ni niego que sea a veces necesario que se puedan establecer determinadas acciones afirmativas que busquen equiparar a determinados grupos sociales que aún no logran superar en su totalidad la afectación y discriminación hacia sus derechos. Empero, estas acciones deben ser excepcionales y nunca pueden implicar la creación o implantación de otros o iguales tipos de vejaciones en contra de la dignidad del otro grupo humano, simplemente, por la razón de su sexo. El espíritu de todas las normas en contra de la discriminación es, justamente, el de impedir y eliminar toda forma de discriminación que atente contra la dignidad del ser humano, más no el fomentar una nueva o diferente discriminación generalizada en contra de otras personas por razón de su sexo, sean muchas o sean pocas las que terminen afectadas en el trato peyorativo de su dignidad. No existe ninguna norma -ni debiera de existirque justifique la vejación de la dignidad de alguien o que le dé preferencia a la defensa de un grupo históricamente discriminado, por encima de otro que supuestamente es el único históricamente culpable y a quien se le deba sacrificar, de manera general, por la razón de su sexo y no de su culpa, haciéndosele padecer una discriminación generalizada que atenta contra su dignidad y sus derechos, en una suerte de venganza o castigo histórico por razón del sexo. Esto no debe existir porque sería inaceptable y extralimitaría toda coherencia, proporcionalidad y razonabilidad, sobre todo, dentro del mismo discurso que sustancia a los derechos humanos y que va en contra de toda discriminación y vejación de la dignidad humana, sean quiénes sean, sean cuántos sean.

\section{LA REGULACIÓN ESPAÑOLA DE VIOLENCIA CONTRA LA MUJER CUANDO EXISTE UN VÍNCULO DE AFINIDAD}

A este tipo de violencia contra la mujer se le suele llamar violencia doméstica; sin embargo, no considero que sea la terminología más adecuada pues esto implica una relación en la casa o en el hogar y la regulación española para esta situación se extiende, incluso, a aquella relación de pareja que nunca hizo vida en común en un mismo hogar.

Ahora bien, en la acusada y existente violencia contra la mujer dentro de la familia o dentro de una relación de pareja, se puede advertir un grave problema social que supera a lo coyuntural como se puede deducir bien de lo que hasta ahora vengo expresando y, sobre todo, de la realidad misma. Además, ante este grave problema, suelen quedar en peligro la vida y la integridad de quienes habitan el hogar, quienes se ven también afectados por esta situación. Hay determinadas circunstancias que en 
cierto modo contribuyen a esta situación. Por ejemplo, las relaciones cerradas y llevadas piramidalmente y que, lamentablemente, aún existen son un excelente caldo de cultivo para producir el desequilibrio de poder que termina por subyugar a uno de los dos en la relación de pareja. Muchas películas, comedias y anuncios publicitarios, fomentan este tipo de entendido piramidal de pareja, donde uno domina y el otro se subyuga. En la mayoría de casos es la mujer la servil y dominada y el varón es el dominante ya que muchas veces los dos han terminado convencidos de que esto es condición, sine qua non, de su masculinidad $y$, en el caso de la mujer, de su feminidad; en otros casos, se entendía que las cosas eran así porque así tenían que ser y no quedaba otra que conformarse e integrarse a ese tipo de relaciones jerárquicas y de dominación. Pese a todo esto, y como no podía ser de otra forma, la razón y la civilización se terminan imponiendo a través del tiempo y, actualmente, podemos advertir que las víctimas de violencia dentro del hogar van venciendo, aunque de a pocos, la tradicional y deplorable cultura de la resignación; aunque es aún insuficiente para hablar de un verdadero y estructural cambio. Las políticas de estado, por supuesto, son un buen instrumento para coadyuvar a superar esta situación; sin embargo, no siempre aciertan en salir al encuentro del problema adecuadamente y se centran en pretender solucionarlo, coyunturalmente, solo desde sus consecuencias y no desde las causas que lo originan, lo que, por supuesto, no logra una eficiencia realmente significativa para acabar por fin con este problema estructural de discriminación y abuso.

Es claro que este es un drama social con el que tenemos que acabar todos los seres humanos comprometidos en una sociedad civilizada y sostenida en el respeto a los derechos humanos para todos por igual. La violencia y los malos tratos en el ámbito de la familia o de la pareja, sobre todo para la víctima, son esencialmente traumáticos. Me explico. En primer lugar, implica un severo fracaso personal, una mala elección y una frustración al saber que esa persona en la que un día se confió era realmente una equivocación que, además, le hace daño; y es que el agresor no es un extraño; pertenece al núcleo íntimo de la vida de la víctima con quien ha compartido privacidad, cosas y tiempo (es su esposo, su novio, su pareja o ex pareja). En segundo lugar, porque el factor de la dependencia económica de la mujer, cuanto mayor sea, mediatizará más su autonomía y la limitará, drásticamente, en su capacidad de decidirse a hacer algo en contra de ese maltratador. En tercer, y último lugar, se añade, a tales circunstancias, la ineficiente y desorganizada respuesta del sistema legal español que a veces parece solo querer cumplir con una apariencia de preocupación hacia lo que diga la opinión pública centrándose en producir normas castigadoras y desproporcionadas que terminan agravando el problema o creando otro, y que, a esta situación de maltrato, no le logra dar una solución significativa y eficiente en términos estructurales, reales y sociales. Parece que el sistema legal español estuviera más preocupado por impactar en la opinión pública dictando leyes agravadas y creando procedimientos que otorgan privilegios discriminatorios y legales por razón del sexo, pero que no están solucionando nada de lo que se supone pretenden extirpar de la sociedad.

Sostengo, que este problema social -de violencia contra la mujer- no se puede resolver solo con estrategias jurídicas que creen privilegios procedimentales y coyunturales de trato legal a favor de las mujeres y en contra de los hombres por razón de serlo, ni simplemente agravando las sanciones del derecho penal y procesal:

La igualdad ante la ley entraña también la garantía funcional de regularidad en los procedimientos de aplicación de las normas. (...) implica que los ciudadanos se hallarán sujetos a unos mismos procedimientos, que su posición en el desarrollo de los procedimientos será la misma y que los órganos jurisdiccionales aplicarán las normas según pautas de coherencia o regularidad. (...) $\mathrm{La}$ igualdad jurídica se manifiesta (...) en los ordenamientos modernos como exigencia de sometimiento a las mismas reglas procedimentales para todos los ciudadanos. (Pérez 2007, página 31 y 32)

Establecido lo anterior, queda claro que lo que se requiere, para lo que queda del problema estructural de la violencia y discriminación en contra de la mujer, principalmente, es de proyectos y programas de intervención que proporcionen una respuesta legal preventiva importante, es decir, salir al encuentro de este problema pero atajándolo desde las causas 
que lo generan $\mathrm{y}$, esto supone, sobre todo, reconocer y gestionar la imperiosa necesidad de potenciar la educación en valores $y$ derechos humanos: en las escuelas, en los institutos $y$ universidades para fomentar una educación que rompa los esquemas tradicionales de dominación de las relaciones de pareja, fomentando la capacidad de crítica y reflexión de quienes serán los próximos padres y madres de familia o, simplemente, parejas de alguien. La actitud violenta y peyorativa contra la mujer no se inicia con el deterioro de la convivencia, sino, por el contrario, mucho antes y durante todo el desarrollo de nuestra vida. El germen está en la falta de respeto que, desde temprana edad, se les infunde y se les alecciona a los jóvenes, de una $\mathrm{u}$ otra forma, dando como resultado que ellos ya ni siquiera lo vean como una falta de respeto hacia el otro, sino como algo normal dentro de una relación de pareja y que deben cumplir porque es el rol que les toca por ser del sexo que son. Se les enseña a menospreciar a la mujer, a cosificarla y a convertirla en un objeto de placer o de mera complementariedad servicial. Mediáticamente, como decía antes - desde los anuncios, carteles publicitarios, películas, series, etcétera-, se nos educa para que el hombre y la mujer aprecien, tengan y mantengan una relación jerarquizada, donde al varón se le presenta como el fuerte y dominador y, con ello, como el poseedor del rol de mando y superioridad y, a la mujer, como lo todo contrario. Por eso es que el fin último de un maltratador de mujeres, realmente, no es lesionar a la mujer; lo que busca es lograr el sometimiento para satisfacer su ansia de dominador porque está convencido que es el lugar que le corresponde como macho dominante. Este último concepto es muy primitivo e irracional, pero, desgraciadamente, aún logra abrirse paso para imponerse en la cultura y conciencia de gran parte de nuestras sociedades modernas, y España no es la excepción.

Esta violencia no cesa, necesariamente, con la separación de la pareja pues el maltratador se resistirá a perder su poder; de hecho, las mujeres divorciados o separadas son un importante grupo de riesgo de esta violencia. El problema, por cierto, como dije antes, se da en todos los estratos de la sociedad; los niveles más elevados en dinero, educación y cultura no están exentos de este grave problema. $\mathrm{Y}$, claro, es absurdo pensar que un problema tan enquistado en los cimientos de nuestras sociedades se pueda solucionar únicamente con leyes coyunturales que busquen proteger a las víctimas y castigar a los victimarios, es decir, actuando únicamente sobre la consecuencia del problema, pero no sobre el problema mismo que genera la violencia; quedarse en ello es insuficiente e ineficiente para un verdadero y estructural cambio social. Lo que nos debe preocupar a todos, incluidas las políticas de Estado, es que no haya víctimas ni victimarios $\mathrm{y}$, para ello, hay que reforzar mucho otras políticas, principalmente, la educativa y no solo las penales y procedimentales de protección o tratamiento sobre casos ya dados o que estén por darse.

Son de relevante atención las diferentes aportaciones que el legislador español ha hecho, como la Ley 38/2002 de 24 de octubre que modifica la Ley de Enjuiciamiento Criminal para acelerar la tramitación de los procedimientos; Ley Orgánica 11/2003 de 29 de septiembre sobre medidas concretas en materia de seguridad ciudadana, violencia doméstica en integración social de los extranjeros; Ley $27 / 2003$ de 31 de julio que regula la Orden de protección de las víctimas de la violencia doméstica, y la Ley Orgánica 1/2004 de 28 de diciembre de protección integral contra la violencia de género, cuyos artículos 61 y 66, incrementan la gama de medidas cautelares para suministrar una tutela integral a la víctima de la llamada violencia doméstica.

La última ley que cito -la Ley 1/2004- me despierta algunas cavilaciones, que considero necesario hacer y que paso, en seguida, a exponer. Se trata del tema sobre el que también llamo la atención en este trabajo y es el que critico muy especialmente.

La Ley Orgánica 1/2004, de 28 de diciembre, de medidas de protección integral contra la violencia de género, otorga un tratamiento preferente $\mathrm{y}$ diferenciado a favor de a una clase de víctima (las mujeres), haciendo una clara discriminación de trato legal contra el varón, por razón de su sexo. Luego, se hace además una diferencia específica de trato para las víctimas especialmente vulnerables que convivan con el autor: se hace una agravación general de los delitos de lesiones solo porque la víctima es mujer o persona especialmente vulnerable y, como si fuera poco, se transformó en delito lo que eran antes faltas de amenazas y coacciones y se hicieron cambios en el delito de quebrantamiento de condena. 
Veremos pues que la Ley Orgánica 1/2004, hizo modificaciones al artículo $148^{\circ}$ del Código Penal, introduciendo los subtipos agravados del tipo básico del delito de lesiones: se introdujo una nueva agravación de las lesiones previstas en el art. $147^{\circ}$ del Código Penal, de tal forma que si la víctima fuera o hubiere sido esposa o mujer que estuviera o hubiera estado relacionada con el autor por una equivalente relación de afectividad, aun sin convivencia, el autor podría ser castigado con una pena mayor que la del tipo base. Esta agravación funciona de forma instantánea, únicamente por la condición de mujer de la víctima y por estar ella relacionada o ex relacionada, afectivamente, al agresor. Además, esta agravante funcionaría también cuando no haya existido convivencia entre la víctima y el supuesto agresor.

Por otro lado, la Ley Orgánica 1/2004 modificó el artículo $153^{\circ}$ del Código Penal y creó una agravante en base a que la víctima sea mujer. Es decir, cuando las faltas -hoy delitos levesno alcanzaban los presupuestos para ser delito, estas se convertían en tales por la mera razón del sexo del agresor y de la agredida; dicho de otra forma, esta modificación hizo que una falta se convierta en delito cuando el que causare el menoscabo psíquico o una lesión de menor gravedad o golpeare o maltratare de obra a otro, sin causarle lesión, sea este un hombre y la víctima una mujer y esposa o que lo haya sido en el pasado o que sea una víctima mujer que esté o haya estado ligada a él -el agresor- por una análoga relación de afectividad, siendo irrelevante que haya o no existido convivencia. Esta es, qué duda cabe, una ley que determina una clara discriminación que atenta contra el principio de igualdad de trato de hombres y mujeres y que no responde a una discriminación que resulte proporcional ni razonable.

Y aún hay más. La Ley Orgánica 1/2004, convertía las entonces faltas de amenazas y coacciones, en delitos. Al delito de amenazas, del artículo $171^{\circ}$ del Código Penal español, se le introdujo tres nuevos supuestos en los que se transformaba a delito las conductas de faltas de amenazas leves por la simple razón del sexo del agresor. Esta transformación automática, de la falta a delito, sucedería si la víctima ha sido mujer y esposa del autor o mujer ligada a él por una análoga relación de afectividad, aun sin que haya existido convivencia (artículo $171.4^{\circ}$ del Código Penal español).
También la Ley Orgánica 1/2004, por la mera razón del sexo, convirtió a las coacciones leves, que constituían solo faltas, en delito. Esta ley agregó un segundo apartado al artículo $172^{\circ}$ del Código Penal español, sancionando como delito las coacciones leves (que en ese entonces eran faltas) cuando la víctima sea o haya sido esposa del autor, o mujer que esté o haya estado ligada a él por una análoga relación de afectividad, aun sin convivencia. Es decir, si la víctima es mujer y vinculada al agresor por una relación matrimonial, ex matrimonial o afectiva, la falta siempre se convertía instantáneamente en constitutiva del delito de amenazas.

Como se puede ver, la pretendida protección integral de la ley Orgánica 1/2004, se gestionó de manera equivocada, pues, al buscar solucionar un grave problema creó otro, provocando la discriminación del varón por razón de su sexo y lo colocó, indudablemente, en una situación de indefensión y desventaja jurídica, únicamente, por la razón de pertenecer al sexo masculino y por ser mujer la supuesta víctima agredida. Por cierto, se dejó fuera de esta mal llamada protección integral a los otros tipos de relaciones familiares y de pareja, como por ejemplo a las relaciones de homosexuales donde una adopta el papel dominante y la otra de dominada y en donde también se producen abusos en contra de la última, que también es mujer y que es víctima del machismo dominador que ha asumido su pareja homosexual que pese a ser también mujer ha asumido el rol que ella cree le corresponde a un hombre.

Como podrán haberse dado cuenta vengo calificando, repetidamente, a las faltas penales como antiguas faltas, y es que debo advertir que la Ley Orgánica $1 / 2015$, de 30 de marzo, de reforma del Código Penal, en su disposición derogatoria única, deroga el libro III del Código, relativo a las faltas y sus penas e introduce, al mismo tiempo, el novedoso concepto de delito leve. Esto afecta no solo semánticamente en relación con las antiguas faltas, sino que modifica sustancialmente la tipicidad y el tratamiento procesal de las mismas desde el nuevo concepto de delito leve. Es decir, en España ya no se habla de faltas sino de delitos leves. Esto lo dejo sentado, pero no lo trato aquí ya que no es el tema propio de análisis de este trabajo. 
Volviendo al condensado análisis que estoy haciendo de la Ley Orgánica 1/2004, de 28 de diciembre, de medidas de protección integral contra la violencia de género, sobre ella debo decir que no intento más que hacer una crítica constructiva y reparadora, pero sin dejar de ser objetivo según corresponde a un análisis serio. Es evidente, entonces, que esta norma adolece de un grave desacierto que provoca, en contra del hombre, un problema de discriminación y vejación peor o igual de grave que el que, supuestamente, pretende solucionar con respecto a las mujeres. Como decía antes, a todas luces, esta norma, está provocando una grave y no razonable discriminación de trato por razón del sexo. Y no se le puede tomar como si se tratara una acción afirmativa, pues esta última, para ser tal, debe y tiene que ser razonable, es decir, no debe provocar una discriminación que, so pretexto de acabar con otra, provoque el detrimento y menosprecio de la dignidad de otro determinado grupo humano. La coherencia y la razonabilidad de una acción afirmativa para enfrentarse al problema de la discriminación y violencia contra la mujer, tendría que estar justificada y sostenida en el rechazo de esta discriminación y violencia sufrida por la mera razón del sexo; esto es lo correcto y coherente. Lo que no puede ser ni es razonable es que el hombre termine violentado y vejado con un trato diferenciado que hacen las normas legales, de manera generalizada, por su mera condición de ser hombre. No se le da ese trato diferenciado y vejatorio, por su dolo o culpa cometida, sino, simplemente, por su sexo y por la denuncia subjetiva -que muchas veces es falsa- de una mujer. La razón de mi rechazo a esta discriminación, se debe, precisamente, a que es inaceptable el menosprecio o el peor trato sufrido, legalmente, por el simple hecho de tener uno u otro sexo. Por eso es que estoy convencido que mi rechazo es justo, razonable y, sobre todo, coherente con lo que defienden y protegen los derechos humanos. Lo que es injusto, irracional e incoherente, es provocar, de manera generalizada, una segunda discriminación que ocasiona un tipo de menosprecio y peor trato solo por la razón de pertenecer al otro sexo. Esto resulta totalmente incongruente con el discurso de los derechos humanos. En España, si una mujer va y denuncia, sin prueba o indicio alguno, a su pareja o marido, sin mediar trámite alguno que lo verifique, la Guardia Civil inmediatamente va a donde esté el denunciado, le aprisionan las muñecas con esposas metálicas $\mathrm{y}$, voluntaria o forzadamente, lo detienen y lo apresan como si fuera un delincuente; y esto ocurre a vista de todo el que esté presente a su alrededor. El denunciado, tiene que pasar la vergüenza $y$ el desprestigio -muchas veces irreparableque implica esto, en su barrio, en la calle, en su casa, con clientes, amigos, hijos y demás familia, etcétera. Luego, el hombre suele pasar al menos un día en el calabozo, pero si la detención es un viernes, suele pasarse todo el fin de semana detenido hasta que el juez instructor termina con el trámite establecido por ley. Esto es desproporcionado porque permite que las muchas mujeres inescrupulosas que existen en nuestras sociedades denuncien falsamente -sabiendo la posibilidad que la ley le otorga solo a ella por ser mujer- para sacar alguna ventaja con la tenencia de los hijos, con la casa que comparte con el marido o dentro de un trámite de divorcio, y, muchas veces, lo hacen incluso asesoradas por sus propios abogados que sin escrúpulo alguno le informan de estos privilegios que otorga la ley a sus clientes, recomendándoles que ellas mientan para que saquen algún provecho judicial aprovechándose de tal o cual norma discriminatoria que beneficia a la denunciante, por falsa que pueda ser la denuncia que, en la mayoría de los casos, ni siquiera se persigue; se puede denunciar falsamente $\mathrm{y}$, en la mayoría de los casos, casi sin que se produzcan consecuencias legales. $\mathrm{Y}$ es aún peor esta situación cuando una mujer denuncia falsamente a su pareja varón o marido por celos, por su infidelidad, por despecho, por enfado, etcétera.

Como se ve, esto es inadmisible, por mucho que se pretenda justificarlo con el consabido argumento que el porcentaje de denuncias falsas es muy bajo. Hay personas y grupos feministas que se amparan en este argumento para defender tamaña vejación; sin embargo, lo único que realmente ampara este argumento es la evidencia que quien lo defiende no ha entendido en nada de qué va el tema de la protección de los derechos humanos y el de la prohibición de discriminación por razón de sexo. En el ámbito de los derechos humanos se defiende y se lucha por evitar que se haga daño a todo ser humano, sea hombre o sea mujer, sea uno o sean miles. El tema de la protección de los derechos humanos es relevante para todo ser que tenga la condición de humano; no se trata de que tenga relevancia a partir de 
un número determinado de afectados para que recién la vejación resulte atendible e importe a los instrumentos de protección de los derechos humanos; tampoco se trata de quitarle relevancia a este problema amparándose en que los afectados por denuncias falsas son solo unos pocos según los números que arrojan ciertas estadísticas -que nunca son fiables-. Los derechos de los seres humanos no son estadísticas o números; los derechos humanos nos son inherentes a todos, no por cuántos seamos, sino por nuestra misma condición de seres humanos. Es tan válida e importante la protección del derecho humano de una sola persona, como lo es el de miles o el de millones de personas. En la coherencia e inalienabilidad de los derechos humanos, es inadmisible que se privilegie a un grupo de seres humanos -so pretexto de protegerlas a ellas- facilitándoles a las mujeres el poder denigrar a otros, so pretexto de criminalizarlos por razón de su sexo, usando mecanismos legales desproporcionados y discriminatorios que posibilitan hacer denuncias falsas, para luego conseguir ventajas judiciales en otras causas o para, simplemente, descargar una suerte de desquite o venganza en contra de alguien que nunca ejerció violencia contra ella, pero que, por lo que sea, la enfadó. Esto, por supuesto, es un despropósito legal y total que es repudiable desde todo punto de vista y, más aún, desde el ámbito de los derechos humanos. La cerrazón de defender un tipo de medidas legales discriminatorias, injustas y desproporcionadas no debe imponerse con el argumento de las estadísticas y el poco número de denuncias falsas $\mathrm{y}$, con ello, de los pocos hombres que resultan denigrados en su dignidad por esta situación. Eso no es hablar de derechos humanos iguales en respeto y dignidad para todos. Los derechos no son mercadería que recién importen según qué peso arroje en kilos o en cantidad de afectados.

Y si nos fijamos en la denominación que se suele usarse con facilidad para referirse a la violencia contra la mujer, también nos encontramos con un término poco pertinente y menos adecuado. Me refiero al uso del término violencia de género que, incluso, podría resultar siendo sexista. Hay algunas voces que, de hecho, lo consideran discriminatorio y poco o nada respetuoso con el principio de igualdad por razón de sexo. Fijar el género solo en las mujeres, como si fuera el único existente o el único merecedor de atención y protección, es ir en contra, precisamente, de lo que defiende la prohibición de discriminación, la que, como hemos visto, se asienta en las normas internacionales y nacionales que he revisado y antes he citado. Tal vez, debiera ser más adecuado utilizar otro término como por ejemplo violencia de la o contra la pareja o la ex pareja; esta denominación hubiera incluido también, por ejemplo, a la relaciones conformadas por personas de un mismo sexo; pero está claro que esto no está aún en el ideario de las preocupaciones políticas actuales ni de esa opinión pública que gusta de salir a las calles cuando se quiere criminalizar a alguien, ni de los grupos feministas que dicen defender el derecho de todas las mujeres. Para estos grupos, las mujeres que sufren maltrato dentro de una relación lésbica no son relevantes para la igualdad que ellas dicen defender.

Nótese también, que la Ley Orgánica 1/2004, de 28 de diciembre, de medidas de protección integral contra la violencia de género, hace que, en cierta forma, se retorne a lo que se conoce como el derecho penal de autor (Claus Roxin 1997) ya que califica la personalidad del varón como condición suficiente y única para suponer, iuris tantum, que su conducta es delictiva, por lo que se produce, paradójicamente, una inversión del principio de presunción de inocencia reconocido en el artículo $24.2^{\circ}$ de la Constitución española. Al mismo tiempo convierte, también, paradójicamente, al presunto agresor en víctima del sistema legal.

Es complicado comprender y sostener que una cachetada o un empellón durante un altercado, sin que haya antecedentes de malos tratos, reciba una pena de hasta un año de prisión, máxime si cuando una agresión igual pero ajena al ámbito de una relación de hombre y mujer se sancionaba antes simplemente como falta. Esto lo entendió bien un Juez de Instrucción del Juzgado número 1 de San Vicente del Raspeig (Alicante), quien gestionó las diligencias urgentes número $2 / 2004$ por un delito de maltrato familiar. Este Juez interpuso una cuestión de inconstitucionalidad en relación con el art. $153^{\circ}$ del Código Penal, reformado por Ley Orgánica 11/2003, denunciando la vulneración del principio de proporcionalidad por entender que era excesiva la cuantía o extensión de la pena en relación con la entidad del delito. Se trataba de un guantazo en la cara que le dio un hombre a su compañera sentimental dentro de una discusión y en presencia de sus dos hijas -sin que existiera ningún hecho anterior de maltrato 
familiar físico o psíquico entre ambos-. Este guantazo produjo una lesión que tardó en curar un día sin tratamiento ni incapacidad pero debía ser castigado con la pena de 9 meses de prisión. La cuestión de inconstitucionalidad planteada por el Juzgado fue inadmitida por el Tribunal Constitucional mediante el Auto de 7 de junio de 2004 (ATC 233/2004). El Tribunal Constitucional justificó la introducción del nuevo artículo $153^{\circ}$ del Código Penal apelando a la percepción social de la escasa respuesta punitiva existente ante el fenómeno de la violencia doméstica y, por ende, según él, de la exigua protección conferida a las víctimas (Fundamento Jurídico $7^{\circ}$ ). En definitiva, el Tribunal Constitucional concluye, que es discrecionalidad del legislador el fijar la cuantía de las sanciones penales y que solo habría un exceso inconstitucional si existiera "un patente derroche inútil de coacción" que convirtiera a la norma en arbitraria y no respetuosa con la dignidad de la persona (Fundamento Jurídico $3^{\circ}$ ). ${ }^{5}$

En relación a lo anterior es pertinente referir lo que el jurista y penalista español Enrique Gimbernat Ordeig (2004), afirmó diciendo que esta situación provocaría que:

(...) cuando se pretende explicar -y ésa es, en efecto, la única explicación plausiblepor qué la conducta de dar un único empujón a la pareja se ha transformado de falta en un delito de lesiones, y que la pena prevista para ese comportamiento puede ser la de siete meses a un año de prisión (art. 133 -sic-, introducido por la Ley Orgánica 11/2003, de 29 de septiembre), y que una única coacción leve del hombre sobre su pareja femenina va a ser castigada con prisión de seis meses a un año (art. 130 del Proyecto contra la violencia de género), con el argumento de que esas acciones aisladas constituyen un indicio de que en el futuro el autor puede cometer ulteriores actos de violencia o de coacciones, los principios que con todo ello se están llevando a la práctica son los mismos que, en su día, inspiraron la Ley de Vagos y Maleantes, y su sucesora, la de Peligrosidad y Rehabilitación Social, que aplicaban medidas de seguridad predelictuales privativas de libertad sobre

5 "Cuestión de inconstitucionalidad (...) Inadmite a trámite la cuestión de inconstitucionalidad (...)", Tribunal Constitucional, Auto 233/2004 de 07 de junio de 2004, en web oficial del Tribunal Constitucional de España, http://hj.tribunalconstitucional.es/es/Resulucion/Show/19802 [Consulta: 7 de noviembre 2018 la base, no del hecho cometido, sino de los que el autor -por su 'estado peligroso'podía llegar a cometer (Página 20).

Ahora bien, pese a mi rechazo que aquí sostengo a cualquier norma legal que provoque situaciones vejatorias, en este trabajo no pretendo dejar de ser correctamente objetivo y menos con este delicado tema. En atención a ello, voy a advertir y reconocer algunos puntos positivos. La Ley Orgánica 1/2004, de 28 de diciembre, de medidas de protección integral contra la violencia de género, es una ley que busca atender a las recomendaciones de los organismos internacionales en el sentido de proporcionar una respuesta global a la violencia que se ejerce contra las mujeres. Más precisamente, considero que pretende responder a la Decisión 803/2004/CE del Parlamento Europeo, de 21 de abril de 2004, por la que se aprueba el programa de acción comunitaria para prevenir, combatir la violencia ejercida sobre la infancia, jóvenes mujeres y proteger a las víctimas y grupos de riesgo. La Ley Orgánica $1 / 2004$, de 28 de diciembre, de medidas de protección integral contra la violencia de género tiene una finalidad fundamentalmente preventiva, educativa, social, asistencial $\mathrm{y}$ de atención a las víctimas, y establece medidas de sensibilización e intervención en el ámbito educativo, potenciando, a través de la publicidad, la igualdad y dignidad de las mujeres, el reconocimiento de sus derechos con sentido social y un largo etcétera. Se fomentan medidas de sensibilización en el ámbito sanitario para la detección precoz de la violencia y atención física y psicológica de las víctimas, incluyendo también la protección de menores. Esto se puede decir que es la parte positiva de esta norma; sin embargo, en el momento que se provocan discriminaciones $\mathrm{y}$ vejaciones que violentan la dignidad de un ser humano por razón de su sexo -sea hombre o sea mujer-, esa norma se desautoriza por sí misma y se convierte en un lastre, sobre todo en el ámbito de los derechos humanos.

\section{PERCEPCIONES FINALES}

No me cabe duda que la Ley Orgánica 1/2004, de 28 de diciembre, de medidas de protección integral contra la violencia de género tiene cosas positivas $\mathrm{y}$, sobre todo, parece llevar el ánimo de corregir la violencia contra la mujer producida por la discriminación histórica que 
ella sufre. Sin embargo, en este ánimo, la norma también parece haber sido demasiado entusiasta en su objetivo y queriendo acabar con algo, ha provocado, precisamente, aquello con lo que pretende acabar, solo que esta vez discriminando al del otro sexo. El resultado, como no podía ser de otra forma, es que la ley de violencia contra la mujer, luego de casi quince años de vigencia, la Ley Orgánica 1/2004, de 28 de diciembre, de medidas de protección integral contra la violencia de género no logra los resultados que prometía ya que el problema sigue presente y vigente, sin presentar mejoras relevantes en cuanto a lo que se suponía quería mejorar. Y es que -y esto es bueno que se tenga muy pero muy en cuenta- el uso del derecho penal debe ser de ultima ratio. No se debe caer en el error de creer que criminalizando al hombre por razón de su sexo -para poder usar y agravar el derecho penal- se puede resolver un problema que radica en la misma estructura de la sociedad. Centrarse en castigar con mayor severidad las conductas que son consecuencias de una discriminación estructural, histórica y cultural, es evidente que resulta ineficiente, en términos de sociedad. Pretender corregir el problema de la violencia solo a través del aumento de las penas y de la agravación de las normas procesales instaurando tratos de privilegio legal en favor de la mujer, sin pensar en todas sus consecuencias, todo esto, es caer en una entelequia absurda de entendimiento que lo único que origina es una esperanzadora falacia sobre un resultado que nunca llegará, simplemente, porque ese no es el camino correcto.

No se puede acabar con un problema estructural solo agravando el castigo o el trato legal para las conductas que son consecuencia de la discriminación que se forja en el tiempo, durante toda nuestra vida, a través de los medios de comunicación, la publicidad, las películas, la escuela y a través de los hábitos de conducta, familiares y amicales que, al parecer, no interesa, real y seriamente, corregir a quienes dirigen nuestros Estados. Menos aún, se corregirá el problema imponiendo otra discriminación que agravia al otro grupo humano. Hay que cortar el problema desde su raíz, es decir, desde sus causas que son las estructuras que lo sostienen. Esto último solo se logra con educación, con más educación y con mucha educación. Entiéndase bien que el saber es poder; una mala educación, es el mejor cultivo para mantener las patologías estructurales de nuestra sociedad: "Saber es poder aprender, poder cambiar, poder estar en desacuerdo, explorar y gozar. Saber es poder ser libre e independiente y también poder amar y apoyar el bienestar de todos los que nos rodean" (Shapiro y Morison, 2000, página 21).

El saber es aquello que nos permite a todos poder ejercer nuestras capacidades de crítica y reflexión que nuestra humanidad nos exige para lograr una vida real, feliz y auténtica. Y cuando digo saber, me refiero al hecho de educarse en valores humanos que nos permitan entender y hacer de nuestra vida, una vida respetuosa y considerada para con uno mismo y para con los demás.

Potenciar la educación en valores y promover las asignaturas que fomentan la capacidad de crítica y reflexión de los ciudadanos, es el mejor y casi único instrumento eficiente para lograr una mejor sociedad que supere verdaderamente las discriminaciones sufridas por determinados grupos sociales, incluida la discriminación por razón de sexo. Las políticas de Estado deben advertir y asumir la necesidad de esta estrategia educativa. Para ello debe esmerarse en reformas profundas sobre el sistema educativo, potenciándolo y dotándolo de todos los medios necesarios para lograr una educación de calidad. La sociedad adquiere sus valores de la educación, lo que, al mismo tiempo, se refleja en sus sociedades; entonces: "No se trata solo de incluir temas o asignaturas específicas, sino también y fundamentalmente de cambiar comportamientos profundamente arraigados en la infancia, en la adolescencia y en el profesorado" (Pazos 2015, página 253).

Lo que no cale y penetre en las conciencias a través de la educación colectiva, no calará ni penetrará nunca a través de la sanción y el mayor castigo:

Se trata de un problema estructural que tiene sus raíces profundas en la dominación masculina (...). La historia nos enseña que los cambios estructurales no 'acontecen' como consecuencia ineluctable de cambios en las condiciones objetivas. (...) El proceso de cambio social es siempre colectivo (...) permite desterrar de nuestra mente viejos esquemas para dar el salto a los nuevos. (Pazos, 2015, página 250)

Lo paradójico es que España hace todo lo contrario: reduce y quita asignaturas fundamentales para la formación reflexiva 
de los niños y jóvenes -como la de filosofía-, reduce el número y las plazas de profesores, reduce el presupuesto de las universidades, no se contratan nuevos profesores ni se saca el número de plazas necesarias, la plana docente está envejecida y sin el relevo de nuevas generaciones que aporten los avances y los nuevos enfoques de la sociedad. Por otro lado, se produce un enorme desgano de los que tienen vocación de enseñar ya que al no potenciarse el ámbito educativo saben que ellos poca oportunidad laboral tendrán, obligándoseles a recurrir a cualquier otro trabajo que les dé el sustento para poder vivir. Todo ello, debilita el sistema educativo y, por supuesto, un sistema educativo con estas deficiencias solo determina que los jóvenes sigan cometiendo y reproduciendo los mismos errores de siempre. Otra consecuencia de esto lo vemos en aquellos que acceden al sistema educativo como profesores pero que cada vez son los menos preparados ya que los mejores y los de vocación prefieren irse a otro país donde se les reconozca su importancia y, con ello, se les dé una estabilidad laboral y un sueldo digno que les permita vivir cómodamente $\mathrm{y}$ concentrados en su labor académica. Se quedan, mayoritariamente, los que no pueden elegir otra cosa y los que no son los más capaces para la enseñanza o, simplemente, los que por contar con alguna facilidad o ventaja puntual, encuentran la oportunidad de ponerse como profesores, y antes de salir al mercado laboral a buscar oportunidades que saben les serán difíciles o imposibles, prefieren quedarse en lo que les resulta ya seguro y fácil, pero esto, no necesariamente, y casi nunca, coincide con su vocación. Luego, sumando a toda esta mayoría de los que acceden al profesorado, nos encontramos con un sistema educativo lleno de profesores que fungen una vocación que no tienen y nunca tuvieron, convirtiendo a los buenos, en la excepción, porque la mayoría de estos últimos, o se van del país o se ponen a trabajar de otra cosa que les ofrezca un nivel de vida más digno y seguro. Luego nos quejamos del nivel educativo español, como si esto fuera algo que surja espontáneamente de la nada o que es culpa de los jóvenes de hoy que no tienen interés por estudiar. El interés hay que impulsarlo con un sistema educativo que funcione bien, con profesores -en todos los niveles- que trabajen con el ánimo de formar a niños y jóvenes críticos y reflexivos, y no con profesores que trabajen con desgano, cumpliendo con lo mínimo aparente para conservar sus trabajos y cobrar sus sueldos de fin de mes, que es lo que, única y finalmente, les interesa y para lo que trabajan. No siempre es así, pero desde hace varios años esta situación se hace cada vez más evidente, más grave y más acuciante. Y si a esto se agrega que en la universidad pública española, ante la insuficiencia de profesores por la falta de plazas, las aulas se llenan con alrededor de cien alumnos y a veces más; claro está, que esto hace inmanejable que un profesor -por bueno que sea- pueda hacer bien su trabajo atendiendo al desarrollo académico e individual de cada alumno, sobre todo cuando debe dar clase a más de un grupo. Luego, toda esta realidad refleja perfectamente el declive de la sociedad. Si no se advierte bien este problema y seguimos creyendo que lo que cambia y corrige los males de la sociedad son los castigos o las mayores penas para los infractores, o la instauración de privilegios legales para quienes resulten afectados, entonces, nada cambiará $\mathrm{y}$, de hecho, sustancialmente, como lo he dicho, el tema que me ocupa en este trabajo, poco o nada han cambiado, pese a todas las medidas agravadas y privilegios otorgados legalmente en el tema que me ocupa en este trabajo. Un buen ejemplo de ello, son los conceptos vertidos en ese capítulo de Sofía o la mujer rousseaunianos que, como hemos visto, siguen vigentes aún en demasiadas cabezas pensantes y notorias de nuestra humanidad.

Tamaña negligencia con el sistema educativo de un país, claro está, no permite la formación crítica de los nuevos ciudadanos y menos la eliminación de un problema estructural que necesita de mentes que no acepten y se den cuenta de que toda discriminación debe ser echada de sus realidades de vida, por el bien de ellos mismos y de la sociedad en general. Seguir generando conciencias distraídas que se dejen llevar por todo lo que hay y que, simplemente, aprenden a integrarse al sistema, como si fueran robots programados, preparándoseles en carreras profesionales que solo los forman para incorporarlos al mercado de trabajo, sin fomentar sus capacidades de reflexión, por supuesto, que no cambia ni cambiará nada y seguiremos siempre en lo mismo: con la discriminación de la mujer y sus consecuencias $\mathrm{y}$, con todas las demás discriminaciones que siguen existiendo históricamente en nuestro mundo. 
La mesa de la realidad está servida con claridad, no hay razón para seguir buscando soluciones "eficientes" dónde no las hay, salvo que se tenga algún interés furtivo, privativo y no reconocido de perpetuar los problemas y los males de la sociedad. Los derechos humanos deben ser eficientes para todos y no quedarse en la simple respuesta mediática o retórica, a veces oportunista, otras veces falsa y hasta manipuladora:

Una utilización meramente retórica o propagandista (...) de manera que podemos encontrar la bandera de los derechos humanos encubriendo realidades o proyectos políticos contradictorios entre sí, cuando no otros que de modo palmario se sitúan en las antípodas de lo que fueron sus supuestos filosóficos. (Prieto, 1996, página 501)

Debo dejar claro también que, aunque se trata de un grave problema (el tema de la discriminación histórica contra la mujer) la solución no puede partir desde la idea de crear una suerte de trincheras, en donde los hombres estén en unas y las mujeres estén en otras, listas para atacar a sus contrarios enemigos, y viceversa. $\mathrm{Y}$ esto es lo que se busca, últimamente, cuando se usa la presión popular para influenciar en la decisión de los jueces, criminalizando, desde las masas, a los hombres que son denunciados como supuestos victimarios de una agresión. Y esto lo hacen masas que no conocen ni han visto las pruebas actuadas dentro de un proceso judicial, pero que, con total desparpajo y desconocimiento de lo sucedido, condenan y repudian a quienes tal vez no sean tan culpables como la supuesta víctima dice, máxime si a ella le han descubierto varias contradicciones y mentiras durante el proceso judicial. Pero esto no le importa a la presión popular, a las masas y a todos esos grupos feministas que promueven ese tipo de presión masiva para hacerse notar e interferir en la decisión final de los jueces. Al final, la lectura que resulta de todo este disparate provocado por la presión popular de esas masas que condenan sin saber, es que cuando hay una denuncia de agresión, violación o malos tratos en contra de una mujer, hay que creerle a ella simplemente porque la que hace la denuncia es mujer, y al o a los denunciados, hay que condenarlos drásticamente, simplemente porque son hombres y no tienen derecho a defensa y los demás -jueces incluidos- no tienen derecho a dudar de la palabra de esta mujer, aunque ella haya caído en contradicciones y se le hayan descubierto mentiras sobre lo que narró en uno y otro momento de los actuados legales. Claro está que esto es un despropósito irracional por donde se le mire. No puede seguir así; esto es inaceptable para el ámbito de los derechos humanos, para la prohibición de discriminación por razón del sexo y para la dignidad de todo ser humano; y quien defienda este tipo de criminalizaciones magnificadas, privilegios procesales y presiones sociales donde las masas son las que condenan, tiene un serio problema de entendimiento sobre lo qué son los derechos humanos.

El problema de la violencia y de la discriminación en contra de la mujer existe, qué duda cabe; sin embargo, es un grave error el creerse que la solución está en ensalzar una especie de disputa épica donde unos sean los malos y las otras las buenas, solo por ser los unos hombres y las otras mujeres.

Este es un problema que ataña a toda la sociedad en su conjunto y, como sociedad, lo correcto es entender y saber que todos somos los afectados, pues la libertad y la igualdad de todos es lo único que asegura la libertad individual de cada uno. No se trata de crear frentes de batalla, una en contra del otro, por razón del sexo. Se trata de alcanzar una sociedad realmente justa donde todos nos reconozcamos parte de una misma humanidad sin distinción peyorativa que pretenda justificarse en el sexo de uno u otro ser humano. Todos somos uno por nuestro vínculo de humanidad: "El fundamento de la unidad social es la misma naturaleza humana" (García, 1970, página 133).

En la humanidad, no hay enemigos naturales por razón del sexo; en todo caso, todos somos parte de la misma trinchera. En este sentido, me gusta mucho el apunte que hace Graciela B. Ferreira al sostener que para tratar el tema de la violencia contra la mujer hay que tener honestidad intelectual y afectiva ya que pese a las denuncias y críticas que ella hace sobre este problema, ello: "No se inscribe en la 'guerra entre sexos' sino en la lucha por un mundo más justo para todos" (Ferreira, 1992, página 11).

No se puede justificar una discriminación legal en donde, por ejemplo, una esposa, con su simple denuncia subjetiva en contra de su cónyuge varón, provoque la detención inmediata del 
mismo, sin que medie flagrancia, indicio o prueba objetiva que determine la supuesta violencia sufrida por esta mujer, o que al menos se pueda inferir, con indicio o prueba reglada. Y la situación se vuelve aún más rocambolesca y abusiva si, como dije antes, tenemos en cuenta que muchas de estas denuncias son falsas, hechas por mujeres inescrupulosas que mienten en el afán de desquitarse o de vengarse por algo, o para lograr alguna ventaja judicial en otro proceso, muchas veces asesoradas por malos abogados, pero que son mentiras que ellas aceptan sostener pese a que saben que su denuncia es una denuncia falsa. ${ }^{6}$ Esta es una clara desigualdad de trato en el procedimiento legal que pretende atajar la violencia contra la mujer y, tal como está planteado, da lugar a que se cometan abusos, sobre todo porque se convierte en un privilegio reservado solo para las mujeres por la mera razón de ser tales; es decir, por razón de su sexo. Esto es un claro error, que atenta contra el principio de igualdad de trato en el procedimiento legal. Esto Luhmann (1969) lo resume diciendo: "Todos son iguales ante el procedimiento"(página 159). Existe pues una innegable conexión entre el Derecho y la moral, y esta moral es la que fundamenta a la comunidad jurídica. Dicha comunidad jurídica:

Se encuentra legitimada en la medida en que se exprese, a través de los derechos asignados a los individuos, la exigencia moral de la igual consideración y respeto de sus miembros. (...) El principio del derecho a ser tratado con equal concern and respect ("igual consideración y respeto") (...) ha de materializarse de manera efectiva en las decisiones políticas y de realización del Derecho. (Faralli, 2007, página 89)

Tengo pues que insistir y reiterar en que se tome mucha atención, que cuando se analiza esta penosa situación provocada por una ley que equivocadamente otorga privilegios e instaura desigualdades de trato legal por

6 "El Estado paga 52.000 euros a un padre que estuvo ocho años sin poder ver a sus hijas por una denuncia falsa", 20MINUTOS.ES, https:// www.20minutos.es/noticia/3488427/0/estado-paga-euros-padre-anos-sinver-hijas-denuncia-falsa/ [Consulta: 11 de noviembre 2018]. Este es un caso actual de una mujer que provocó un daño irreparable para el padre y para sus dos inocentes hijas. Esta mujer denunció falsamente a su esposo por maltratos en contra de ella y, como si esto no fuera lo suficientemente grave, además lo denuncio por agresión sexual en contra de una de sus niñas. Luego, se descubre que las denuncias eran falsas y que el padre injustamente fue separado y prohibido de ver a sus hijas por 8 largos años; y ese es un daño incurable para el que no existe indemnización económica que lo remedie. El daño ya está hecho. razón del sexo, la respuesta fácil que se suele defender, para esta legalidad defectuosa, es la que se escuda en los porcentajes de cantidad y estadística; como si el tema de los derechos humanos, resulta ahora, que se limita a los números y a las estimaciones de computo. En esta situación -léase error- se argumenta diciendo que el porcentaje de denuncias falsas de mujeres es muy bajo. Sí claro, es posible o no que las estimaciones que se hacen sean así; sin embargo, cuando hablamos de derechos y más aún cuando hablamos de derechos humanos, el argumento de la cantidad y de los porcentajes de afectados salen sobrando. Serán válidos, tal vez, para el derecho penal cuando aplica sus agravantes o atenuantes, pero en los derechos humanos, no. Como anote, ut supra, en derechos humanos importa tanto el derecho de un ser humano como el de diez mil. Es que, en derechos humanos, no se trata de proteger cantidades o porcentajes a partir de los cuales recién se consideren atendibles los derechos de los demás. En derechos humanos se protege la calidad humana, no la cantidad. Entonces, por muy bajo que se diga que es el porcentaje de denuncias falsas que hacen las mujeres, esto ya deja en evidencia que la norma legal que regula un trato desigualitario, está provocando y permitiendo un abuso de derechos en contra de seres humanos inocentes, que por mucho que pertenezcan a esa estimación del pequeño porcentaje, lo cierto es que ellos nunca ejercieron la violencia que denuncia, falsamente, esa mujer, y solo han sido víctimas de una norma discriminatoria que los maltrata por su condición de hombres y que los coloca en una situación de indefensión legal desproporcionada, lo que, desde los derechos humanos, resulta completamente inaceptable e injustificable. Ese porcentaje de denuncias falsas, al que se apela como justificación de semejante situación, por ínfimo que sea, responde al sufrimiento de seres humanos varones sometidos a un maltrato de sus derechos, simplemente porque existen normas legales que dan la posibilidad de que se pueda abusar de ellos, casi impunemente. Estas situaciones son las que tienen que ser corregidas de inmediato, pues el derecho de uno es el mismo que el de todos; el derecho de unas no justifica el maltrato del derecho de otros. La discriminación y la violencia en contra de la mujer son detestables, desde todo punto de vista; eso es innegable. Ahora bien, esta discriminación y violencia, es tan 
igual de deleznable que la discriminación legal que coloca en condición de desigualdad, de desventaja y de indefensión a otro ser humano, sencillamente, por pertenecer al sexo masculino: "Y es que "igualdad" es término normativo: quiere decir que los diferentes deben ser tratados y respetados como iguales y que, siendo ésta una norma, no basta enunciarla, sino que es necesario observarla y sancionarla" (Presno, 2015, página 368).

Hay que entender que una sociedad justa requiere de una ética social viva y eficiente, donde nuestras relaciones con los demás se enmarquen en la conciencia de humanidad generalizada y fundida en la humanidad y en el valor de todos:

Toda persona humana debe contar con una conciencia y convicción de sus valores y derechos humanos. Esto es trascendental para lograr una verdadera paz social (...). Es clara la superioridad de la convicción como mejor instrumento para lograr una real eficiencia en el respeto hacia los derechos humanos más allá de la formal obligación legal que simplemente obliga a respetarlos. (Contreras, 2017, página 104)

Siempre debemos ponernos en el lugar del otro, u otra, pero no viendo a ese otro como si fuera un otro ajeno u enemigo. Hay que ver a ese otro, por equivocado que esté en su comportamiento, como si fuéramos nosotros mismos. Se trata de reconocerse en ese otro como yo. Este reconocimiento se sustenta en la convicción de saber que todos pertenecemos a una misma humanidad, más allá y por encima de cualquier estadística o condición de sexo u otra situación cualquiera:

Es a partir de la consideración del otro que se ponen los valores reconocidos de un orden más eminente que todo interés egoísta y que toda conveniencia de un grupo particular (...) la teoría de los valores, en sus contrapuestas expresiones, destaca, junto a los valores de la libertad individual y de la solidaridad social, el de la universalidad humana. (Dujovne, 1959, página 446 y ss.)

Es desde estas convicciones en las que el Derecho y las políticas de Estado deben empezar a gestionar las leyes para evitar caer luego en discriminaciones desproporcionadas que terminan menospreciando el derecho del otro grupo humano por la simple razón de su sexo, como en el caso que me ocupa. Al mismo tiempo, hay que implantar esta convicción en la enseñanza, para que los niños y jóvenes que se forman entiendan que la violencia contra la mujer es absolutamente inaceptable, precisamente, por esa humanidad que nos une a todos por igual y que nos exige el no menospreciar al otro u otra, porque ese otro también soy yo, sea hombre o sea mujer: "No se encuentra en todo el mundo hombre alguno separado por completo de los demás (...). La idea de la "naturaleza del hombre" tratada como una isla, desvinculada de toda comunidad social (...) es un mito sin realidad" (Villey, 2016, página 114).

Lo anterior me lleva a recordar las alumbradas palabras que un conocido poeta inglés escribió en el siglo XVII, John Donne, las que resultan muy oportunas en el actual estadio de mi trabajo:

Ningún hombre es una isla entera por sí mismo; cada hombre es una pieza del continente, una parte del todo (...): la muerte de cualquier hombre me disminuye, pues estoy unido a toda la humanidad; en consecuencia, nunca preguntes por quién doblan las campanas; doblan por ti (Donne, 1959, páginas 108 y 109).

Así pues, para lograr mi derecho propio, debo aprender a respetar el derecho de los demás. A esta convicción, de reconocerse en el otro como uno mismo desde la humanidad que nos une a todos por igual, se le conoce como la Teoría de la empatía del reconocimiento:

La empatía del reconocimiento significa reconocerme en el problema de ese otro, pero no en su afectación particular, sino en su humanidad, que es la misma que yo tengo y, en eso sí que me puedo identificar perfectamente para negarme a toda indiferencia o desapego. El poner en práctica la empatía del reconocimiento es una consecuencia lógica de una educación correcta en valores humanos. (Contreras 2016, página 63)

Todo lo cual me lleva, finalmente a concluir, que toda discriminación vejatoria $\mathrm{y}$ desproporcionada es mala $\mathrm{y}$, por ende, que toda discriminación así, es negativa 
para la sociedad tanto en su existencia como en su pretensión de servir de instrumento para dar solución a otra que se suponga de mayor gravedad.

\section{FUENTES DE INFORMACIÓN}

\section{Fuentes bibliográficas}

Barranco Avilés, María Del Carmen (1996). El discurso de los derechos. Del problema terminológico al debate conceptual. Madrid, España: Dykinson.

Donne, John (1959). Devotions. Upon emergent occasions. Michigan: The University of Michigan Press,

Dujovne, León (1959). Teoría de los valores y filosofía de la historia. Buenos Aires: Paidos.

Faralli, Carla (2007). La filosofía del derecho contemporánea. Traducido por José Iturmendi Morales, María José Falcón y Tella y Juan Antonio Martínez Muñoz. Madrid: Facultad de Derecho-Universidad Complutense.

Ferreira, Graciela (1992). Hombres violentos. Mujeres maltratadas. Buenos Aires: Sudamericana.

García Estébanez, Emilio (1970). El bien común y la moral política. Barcelona: Herder.

Giménez Gluck, David (1999). Una manifestación polémica del principio de igualdad. Acciones positivas y medidas de discriminación inversa. Valencia: Tirant lo Blanch.

Lonzi, Carla (1981). Escupamos sobre Hegel. Barcelona: Anagrama.

Luhmann, Niklas (1969). Legitimation durch Verfahren. Neuwied: Luchterhand.

Montoya Melgar, Alfredo dir. (2007) "Significado de la Ley Orgánica para la igualdad efectiva de las mujeres y hombres". En Igualdad de mujeres y hombres, 25-78. Madrid: Civitas.

Pazos Moran, María (2015). Desiguales por ley. Las políticas públicas contra la igualdad de género. Madrid: Catarata.

Pérez Luño, Antonio (2007). Dimensiones de la igualdad. Madrid: Dykinson.
Prieto Sanchís, Luis (1996). "Derechos fundamentales". El derecho y la justicia. Vol. 11 de En Enciclopedia iberoamericana de filosofía. Edición de Ernesto Garzón Valdés y Francisco Javier Laporta. Madrid: Trotta.

Rousseau, Juan Jacobo (2011). Emilio o de la educación. México D.F.: Porrúa.

Roxin, Claus (1997). Fundamentos. La estructura de la teoría del delito. Tom. 1 de Derecho Penal. Parte General. Traducido por Diego-Manuel Luzón Peña y otros. Madrid: Civitas.

Villey, Miche L. (2016). Filosofía del derecho. Traducido por Evaristo Palomar Maldonado. Madrid: Berit Cultural.

\section{Fuentes hemerográficas}

Contreras Ugarte, Jesús Víctor Alfredo (2017). "Decisiones políticas en materia ambiental: Reflexiones desde la ética weberiana y desde la fuerza trascendental hegeliana", Revista Internacional de Direito. Derecho ante los desafíos de la globalización IV, $1^{\circ}$ : 103-128.

Contreras Ugarte, Jesús Víctor Alfredo (2016). "Derecho, sostenibilidad y conciencia de humanidad: Una propuesta desde la filosofía de Hegel". Protección de los derechos fundamentales en un contexto global. Núm. III de Direito e justiça. Coordinado por Ignacio García Vitoria y José Manuel Almudí Cid, 4364. Lisboa: Juruá.

Gómez Orfanel, Germán (2008). “Acciones positivas a favor de la mujer en España: doctrina, jurisprudencia y legislación". Anuario de derechos humanos. Nueva época 9: 379-402.

Gimbernat Ordeig, Enrique (2004). "Prólogo a la décima edición”. En Código penal. Madrid: Tecnos.

Presno Linera, Miguel Ángel (2015). "Dignidad humana y libre desarrollo de la personalidad". En Dignidad humana y derecho fundamental. Dirección de Ricardo Chueca, 361-393. Madrid: Centro de Estudios Políticos y Constitucionales.

Shapiro Rok, Ester y María Morison Aguiar (2000). "Saber es poder". En Nuestros cuerpos, nuestras vidas. Edición de Veronica NielsenVilar, 19-22. Nueva York: Siete Cuentos. 


\section{Fuentes electrónicas}

Aitor Hernández-Morales (2017). "Un juez de Portugal justifica la violencia de género cuando la mujer es infiel”, El Mundo. Recuperado del sitio de internet http://www.elmundo.es/socie $\mathrm{dad} / 2017 / 10 / 23 / 59$ edf4f6468aeb293b8b45ab. html

Tribunal Constitucional de España (2004) "Cuestión de inconstitucionalidad (...) Inadmite a trámite la cuestión de inconstitucionalidad (...)», Auto 233/2004 de 07 de junio de 2004. Recuperada del sitio de internet http:// hj.tribunalconstitucional.es/es/Resulucion/ Show/19802.

20 MINUTOS (2018) “El Estado paga 52.000 euros a un padre que estuvo ocho años sin poder ver a sus hijas por una denuncia falsa". Recuperado del sitio de internet https:// www.20minutos.es/noticia/3488427/0/estadopaga-euros-padre-anos-sin- ver-hij a sdenuncia-falsa/

RVPRODUCTIONS (2011), "Denuncias falsas en España por mujeres. Violencia de Estado. Lobbys perversos". Recuperado del sitio de internet, https://youtu.be/3zhAOSf3lt4

El Mundo (2017). "Un eurodiputado polaco: 'Las mujeres deben ganar menos porque son más débiles"". Recuperado del sitio de internet, http://www.elmundo.es/sociedad/2017/03/02/ 58b7e4a222601ddb078b45b3.html

\section{Legislación}

Carta de Derechos Fundamentales de la Unión Europea, Niza, 07 de diciembre de 2000.

Carta Social Europea, Turín, 18 de octubre de 1961.
Código Penal español. (BOE núm. 281, 24 de noviembre de 1995).

Constitución Española. (BOE núm. 311, 29 de diciembre de 1978).

Convención para la Eliminación de todas las Formas de Discriminación contra la Mujer, Nueva York, 18 de diciembre de 1979.

Convenio para la Protección de los Derechos Humanos y de las Libertades Fundamentales, Roma, 04 de noviembre de 1950.

Declaración de Beijing, Beijing, 15 de septiembre de 1995.

Declaración de Copenhague Sobre Desarrollo Social, Copenhague, 12 de marzo de 1995.

Declaración Universal de Derechos Humanos, Paris, 10 de diciembre de 1948.

Declaración y Programa de Acción de Viena, Viena, 25 de junio de 1993.

Ley Orgánica 1/2004, de 28 de diciembre, de medidas de protección integral contra la violencia de género (BOE núm. 313, 29 de diciembre de 2004).

Pacto Internacional de Derechos Económicos, Sociales y Culturales, Nueva York, 16 de diciembre de 1966.

Pacto Internacional de los Derechos Civiles y Políticos, Nueva York, 16 de diciembre de 1966.

Protocolo 12 a la Convención Europea de Derechos Humanos, Roma, 04 de noviembre de 2000. 